\title{
The Aesthetization of Moral Education in Traditional "Literati Painting"*
}

\author{
Ying $\mathrm{Xu}$ \\ Zhuhai College of Jilin University \\ Zhuhai, China 519041
}

\begin{abstract}
Literati painting" is Chinese elite culture, which is not only an important symbol of Chinese painting, but also an important symbol of Chinese philosophy and Chinese aesthetics. The formation of "literary painting" was formed through the polishing and perfection of the dynasties. The "literati painting" presents the inner world and spiritual pursuit of the literati painters of the dynasties. Their styles and forms are diverse but the inner humanistic feelings and personal charm in their paintings are the same. This paper analyzes the aesthetic value of moral education of literati painting from the overview of the development of literati painting, literati painter's educational background, literati painting philosophical thinking, literati painting aesthetic psychology and gentleman theme of literati painting, providing aesthetic education material for today's moral education.
\end{abstract}

Keywords-tradition; literati painting; aesthetic; moral education

\section{INTRODUCTION}

In "Guanzi ", it is said "the plan for one year is like a tree sapling; the plan for ten year is like a tree; the plan for the whole life is like a tree man." "Cultivating people with virtue and moral education coming first is the fundamental value orientation of school education in China, which is determined by China's history and traditional culture. It is also the inevitable need to cultivate high-quality talents with national self-confidence and national strength. With the reform of China's economic and political system, the moral values and ideology of the general public have undergone great changes, and the moral and ethical values tend to be diversified. Since the 1970s and 1980s, the moral education has taken indoctrinating stylized education, which inevitably led students to formally complete tasks, and the moral education is not effective. It neglects students' inner emotional needs, and lacks humanities. In recent years, moral education has received more and more attention, so finding a solution from a new perspective is an urgent need of educators. The painter Zhang Yanyuan of the Tang Dynasty commented in the remarks of "The Famous Paintings of the Past Dynasties" that "the artists educate people, help people, exhaust changes, and measure the faint. They have the same contribution with the six nations, and

*Project: 2017 National Humanities and Social Sciences Project Research on the Moral Education Aesthetics of "Traditional Literature Painting" (Project No.: 17BJR01067) work in the four seasons. They get the inspiration from nature and thus create the work." It is the viewpoint the author puts forward from the perspective of the function of painting. The inherent meaning is that painting is not only painting, but also has an educational influence, helping people to establish correct moral behavior norms, so that individuals have noble personality. "Educating and helping people" refers to the social nature of art education, which maintains the ethics of society, focuses on the influence of group consciousness, thus promoting the stable development of the whole society, which is not only the embodiment of art value, but also the ultimate value of education. The aesthetization of moral education is a new mode of education.

General Secretary Xi Jinping wrote in "A Series of Important Speech Readers" that "the rich philosophical thoughts, humanistic spirit, educational thoughts, and moral concepts of Chinese excellent culture also contain important revelations that solve the problems faced by contemporary human beings, who can provide useful enlightenment for transforming the world and governing the country as well as conducting moral construction." [2] Today, our education can go higher and further only through learning useful ideas and spiritual nutrition in the excellent traditional culture of the Chinese nation.

Literati paintings are a unique style system in Chinese painting. From the perspective of meaning expression, the literati painter is a cultural person with comprehensive and profound cultural accomplishment. In creation, they emphasize the expression of individuality and combine various artistic forms such as poetry, book, painting and printing. In modern times, Chen Hengwu believed that literati painters must have four elements: character, learning, talent and thought. From the perspective of philosophical theory, the literati painting contains the "humanity of heaven" of Confucianism, "the natural nature of heaven" of Taoist thought and "the spirituality of heaven" of Zen thought. The literati painting began in the Tang Dynasty, developed during the Song Dynasty, and flourished in the Yuan Dynasty and even the Ming and Qing Dynasties. The literati paintings of several dynasties reflect the profound traditional cultural connotations of China and have always received the attention and research of scholars at home and abroad. 


\section{OVERVIEW OF THE DEVELOPMENT OF LITERATI PAINTING}

The academic circles have always had great differences on the origin of literati painting. The formation and development of Chinese literati paintings have undergone a rather slow evolution process, which is a cultural phenomenon that is influenced by many factors in Chinese feudal society. During the early Jin Dynasty, Yao Zui of the Wei, Jin and Southern and Northern Dynasties put forward the creative attitude of "not learning for others but for selfentertainment." In the Tang Dynasty when the poetry was popular, the poet Wang Wei first putting the poetry into painting by saying "there are paintings in poems and poems in the paintings", which marks the beginning of the emergence of literati paintings; Dong Yuan and Juran of the Five Dynasties pursued the plain and innocent feelings in the landscape paintings, providing a direct artistic norm for the style-oriented development of literati painting; literati painting was actually born in the Song Dynasty, a culturally prosperous society, and originated from the national policy of "emphasizing culture instead of armed strength " in the Song Dynasty. The status of literati is very high, and the literati's thoughts are active. Su Shi of the Song Dynasty put forward the theory of evaluating paintings: "Evaluating a painting according to the form is naive". He first proposed the concept of "literary painting" and advocated that "poetry and painting are consistent". He vigorously advocated the combination of poetry and painting, and formed the most prominent characteristics of literati painting. In the Yuan Dynasty, literati painting became the dominant literati painting genre. Due to the ruler's neglect and exclusion of the Han people, the literati mostly lived in seclusion. They concentrated on studying painting away from politics. Their creation is relatively free, and their works show their own living environment, taste and ideals they focus on literature and pen and ink, pay attention to the combination of calligraphy and poetry, books and paintings. The Han people re-ruled China in the Ming Dynasty, and the literati reemerged. Since the first emperor of the Ming Dynasty paid more attention to the generals and the centralized system, the eunuchs were in power and the literati lost their advantage in the rights. In the face of such a situation, the Ming literati preferred to be hermit. In the late Ming Dynasty, Dong Qichang proposed the "North and South Zong" painting theory to revitalize the literati painting, and it also had a continuous impact on the paintings of the Qing Dynasty. In the middle and late Qing dynasty, literati painting began to expand from expressing the artist's own feelings and thoughts to expressing society, sympathizing with the people's sufferings and lashing social reality. The most representative literati painters are "Eight Talents of Yangzhou."

\section{THE EDUCATION BACKGROUND OF LITERATI}

Literati paintings use the four elements of character, learning, talent, and thought as the aesthetic criteria. However, the experience of these four elements is inseparable from the educational background of scholars. Therefore, the study of the moral education of literati painting must first find its roots and start from the enlightenment education of literati.

- Taking Confucianism as a life orientation and studying Confucian classics Confucianism is the orthodox Chinese feudal society which lasted for more than 2,000 years. Confucianism became the standard textbook for later scholars, profoundly affecting all aspects of Chinese traditional culture and art. The influence of Confucianism on the literati has penetrated into the bone marrow. The idea of "when you are poor, you should cultivate your personal qualities. When you are rich, you must benefit the people of the world." has become a kind of creed of life. There are "eight items" of "research all the things to get true knowledge to cultivate oneself, manage the family, govern the country and make the world peaceful". This is a Confucian thinking logic. This kind of logic emphasizes that it is necessary for gentleman to cultivate the spirit to expand its goodness, and help the outside world, so that it can be sanctified. Internally, it is self-cultivation, and to the outside it is helping others. Self-cultivation is the first, because a gentleman should be righteous before teaching others, which is the so-called "being able to establish oneself, one should help others to do so". "Benevolence, righteousness, rituals, wisdom and faith" is the literati's life standard. What Confucius wants to cultivate is the "benevolent man" who can carry out benevolence and morality. "Benevolent man" is the ideal figure in Confucius's mind. Confucius regards "benevolence" as the starting point as well as the destination of its education, as a criterion for self-cultivation, self-improvement and self-fulfillment in the process of education; it promotes the healthy development of personality. [3] Confucius has made some norms on people's words and deeds: paying attention to personal cultivation and conservation, extremely emphasizing ritual and culture, and the emotions should be deep and mellow, with sorrows and savings, and emotions are not lost in neutrality. . He put forward the term "literate and polite", advocated that "never sit on the seats that are not right." and thought that the harmonious literary and rational development can be called a gentleman. This is his standard for evaluating human beings and the specifications of educating people.

- It is also the educational creed of ancient literati to use art to decorate the body and cultivate the virtues. "Music education" reflects the earliest art education content in China. The purpose of educating and cultivating people in the form of art is to cultivate a person with a sound personality and "becoming a happy person" is the realm of achieving personality. Confucius noticed that art has an educational function that is deeply rooted in people's hearts and perfects personality. "Art" has become an important part of the cultivation of the gentlemen. "The Analects of Confucius Taibo" wrote: "Prospering in "Poetry", standing because of courtesy, and completing from 
music." "The ceremony here is equivalent to a set of behavioral norms, including law, etiquette, ritual, and ethics, etc. The ritual focuses on the norm and has coerciveness while music is the emotional catalyst. Through art, the inner feelings are cultivated, adjusted, balanced, and subtly influence people's sense of identity on the hierarchical order of this ritual, ritual order, harmony, ritual and music. The relationship between "ritual" and "le" in education is the relationship between moral education and art education.

- Integration of poetry, books, paintings, and prints. We should emphasize the ability of both academic knowledge and art of painting, and focus on the breadth of knowledge education. In ancient China, influenced by traditional Confucian education, poetry is a compulsory course for literati literacy training. Almost all the ancient Chinese literati can write poems. After the 7th and 8th centuries, poetry became the art activity that most literati can actively participate, feel convenient and accommodate. The tradition of "poetry expressing aspiration" made the literati seem complacent in this matter. Calligraphy is also a must-have writing skill for literati. Su Shi found the intrinsic connection in poetry and calligraphy, which are all originated from the literati's mind and thought, and subject to the needs of the literati's spiritual life. Poetry and calligraphy complement each other. The saying goes: "the lack of painting can be supplement by words". If the thoughts that cannot be expressed in the picture, or can't be expressed clear enough, or there is the need for picture composition, the short topics and verses can make the picture interesting. In the Yuan Dynasty, poetry, painting and calligraphy became one, and this feature of literati painting is also an important symbol to distinguish other painting forms. It can be seen that the literati's cultivation and learning of literati paintings is comprehensive.

\section{THE PHILOSOPHICAL THINKING OF LITERATI}

Confucianism, Taoism, and Buddhism, as the three mainstream thoughts and the constituent elements of the main ideas of Chinese feudal society for more than two thousand years, have laid a deep imprint on the ancient Chinese literati thought. The intrinsic composition of the traditional Chinese literati paintings has been deeply influenced by the confluence of Confucianism, Taoism and Buddhism.

\section{A. Confucianism}

From the perspective of Confucianism, Confucius put forward the idea of "devoting to Tao, according to $\mathrm{Yu}$, relying on the benevolence, and traveling in the arts".

He thinks "Tao" is the goal of life. The ultimate expression of art is also attributed to the level of Tao. The moral standards such as "benevolence and righteousness, neutrality" advocated by Confucianism should be reflected in the paintings, as reflected in "Book of Changes". The antagonism and unity of yin and yang, rigid and soft, and the pursuit of "harmony" in aesthetics also deeply influence the development of literati painting. Their "educationalization", "ethical theory", "literacy" and "neutralization" have a profound impact on Chinese literature and painting. As Zhang Yanyuan said, "The artist educates people, help people, exhaust changes, and measure the faint. They have the same contribution with the six nations, and work in the four seasons." The Confucian orthodoxy influenced the value of the ancient literati in the creation of painting. Here "humanity" refers to the "painting method".

\section{B. Taoism}

In the entire feudal society, Taoism has always been a contrary complement of Confucianism. Confucianism and Taoism also have great complementarity in another respect. Because of this, Taoism has also had a great influence on the creation of literati painting. Zhuangzi's freedom is the artist's best creative state, and the realm of "the Tao way following nature and unity of heaven and man" is the highest realm of painting. As Fu Zai said, "the art of Zhang Gong is not the painting but the truth." When knowing the fact, he ignores the techniques and abstracts the meaning. The essence of things is in its soul instead of appearance. He becomes the apprentice of gods' art here, in line with the principle of Tao, is the realm that literati painters pursue. For example, Ni Yunlin, Shen Zhou, and Shi Tao's landscape paintings are all in the pursuit of this assimilation with nature and creation. The creation of literati painting emphasizes "the nature of Taoism", "the creation of the mind", and "using the nature to creation", and this idea is born out of Taoism. The paintings of the literati painters also conform to the principle of "Tao". Here, "painting is the way", namely the "natural law". [4]

\section{Zen Thought}

Buddhism gives Chinese painting art a kind of Buddhist interests in aesthetic meaning. As a great poet who uses Zen to paint, Wang Wei is greatly influenced by Zen Buddhism. In his later years, he paid attention to meditation and quietness and regard everything in the world with peace of mind. The pursuit of Buddha and self in Zen thoughts has caused more literati painters to return to thinking and questioning the painting itself, the painter himself, and the painted object. What is eternal? What will not be born or die? In the view of the Zen ancestors, the "Zen Law" is the "heart law", which means the heart is the Buddha", and the "quiet, empty, clear, light, and far" presented in the Zen world is exactly the realm that the literati painter pursues. Dong Qichang started from the word "empty" in Buddhism, reflecting the "infinite method" in his paintings. Mr. Jin Dongxin realized the eternal value of life like the golden stone from the "Golden Stone". [4]

\section{Aesthetic Psychology of Literati Painting}

The reason why the literati painting works last for a long time is closely related to the author's aesthetic taste. The 
level of aesthetic taste is inextricably linked with the pattern and mood.

\section{A. Truth}

"Truth" is the soul of literati painting. As far as the truth of the object is concerned, the literati painting can express the emotion, the quality and the common sense; in terms of the truth of the soul, the literati painter maintains the free character and abandons the fame and fortune, thus being more capable of expressing feelings.

When the principle of unity of the heaven and human enter the aesthetic area, it is reflected as the aesthetic quality of "truth". "Truth" embodies three meanings in literati painting. First, the object is true. As Jing Hao said "painting is painting. You should observe the object and find its true appearance. If you like painting the landscape, you need to know the source of the image." The tree is born because of its nature. "It is obvious that "truth" is a nature endowed by nature. Therefore, there are terms such as "describing the truth" and "pointing out the truth" in painting, which means expressing the inner essence of the object. Second, the soul is true. It includes both emotions and ambitions, which can be called meaning. Confucianism and Taoism emphasize the truth of the soul. As "Zhuangzi" said: "The truth is sincere." If the painting is not sincere or refined, it can't move people... The truth is endowed from the nature, so it naturally can't be changed. The saints follow nature and value and regardless convention." "The Mencius Li Lou" said: "The honesty is also the way of heaven as well as the way of thinking of the people." The literati painting are the product of the literati's interest. Therefore, "painting is the heart painting" that express the unique spirit, Deng Chun records the words of Su Shi: "literature can reach my heart, and the painting is just the right thing." The prodigy of the Ming Dynasty $\mathrm{Xu}$ Wei put forward the "true self" theory, which literally means a sincere and conscious self. Third, the root is true. That way is true. This truth not only transforms all things, but also contains the image and the human heart, which is the common nature of the world. Shi Taoyun: "my ambiguity is not in the mountains and rivers, but the spirit is driving outside the mountains and rivers." $\mathrm{Bu}$ Yantu of the Qing Dynasty also said: "Making big things must use large things, so scholars with high expectation must first have a view of the broad sky. They exist in the corporeality, and seek for the intangible height." From the three meanings, it can be seen that the literati painting pursues the "truth" of aesthetics. The literati painting can not only show the normality, the spirit and the quality of the object, but also maintain a free and pure soul. It ignores fame and benefit, and expresses spirit. More importantly, the literati painting adhere to the tradition of harmony between man and nature. No matter the intention before painting or the realm after painting, they pursue the natural realm.

\section{B. Pure}

"Pure" is the realm of literati painting. It is characterized by the creation of an empty and intelligent artistic conception with the image of loneliness and quietness, to express the characteristics of high and far-reaching features. In the creation of artistic conception, it often has the characteristics of emptiness and indifference. As a literati's character, pure is in the same vein as the "Celebrity" character of the Wei and Jin Dynasties, and has a strong aesthetic taste. In A New Account of the Tales of the World, there are a large number of tasting vocabulary based on pure, including lucid, fluent, luxuriant, fresh, gentle, faraway, and light and so on. "Pure" gives a unique aesthetic connotation on the level of philosophy. First, the literati pursue the Taoist ideology, adhere to their initial intentions of seeking the laws of the world's origins, put aside all distractions and pollution, and not be bound by the secular and fame and fortune to maintain a quiet and pure state of mind. Second, it emphasizes the human feelings that naturally emerge from the true and sincere heart. The "pure" in Confucianism has a strong ethical and moral connotation. It requires the bureaucrat to be honest and upright. The "pure" of Bo Yi is the "pure" of the integrity of the martial arts, which is used to summarize the attitudes of the hermits in the Qing Dynasty. Xunzi gives "pure" a high degree of attention. He believes that "the original pure is clear, and the original turbidity is turbid." It means that only when the individual's heart is clear, his behavior and ambition can be "clear". This view plays a major guiding role in personal cultivation. Third, Hui Neng has a famous proverb: "Bodhi has no trees, and the mirror is not the platform." Since there is nothing originally, the dust can't make it dirty. "The inner meaning of this advocacy and "three noes" is to clear the mind. That is to eliminate distracting thoughts and to cleanse people's hearts. It can be seen that the ideal world of Zen is to reach the realm without dust. "Achieving the Buddha's Land" has achieved the clearing of the language. It is precisely the pure, empty, and clear mental state and lifestyle of Zen that makes it more popular among literati. And this kind of aesthetic taste naturally affects their aesthetic creation, and their works are therefore more "clear" and beautiful. [5]

The theme of literati painting also reveals the aesthetic connotation of "pure". The four gentlemen's subjects Plum, orchid, bamboo, and chrysanthemum all have high and elegant temperament, unconventional, and different noble qualities. The literati ink-and-wash landscape painting has the "light" aesthetic ideal of "indifferent but beautiful" Taoist thought, and the picture presents a quiet and light tone. To reach the realm of "pure", we need to achieve the state of inner peace. Only the inner peace is quiet, and is not inflammatory or profitable, less private, and indifferent can the spirit be focused, and the body can be deepened, thus wholeheartedly entering the realm of ecstasy.

\section{Elegant}

"Elegant" is the external temperament of literati painting. Elegant is opposite to the vulgar. Only when "there is no common voice in the ear, no vulgar things in the eye, and no common things in the chest" can they have the calmness from the pen to the ink. Elegant pays attention to the style; it is not enough to temper the pen and ink. The painter must be literati. After reading many books, they can have the gentleman's style. "Elegant" means orthodox and legitimate. In the aesthetic field, the aesthetic category opposite to 
"elegant" is "vulgar". Vulgar things have several aspects in the aesthetic definition of literati painting. First is gorgeous, which is also called secular flavor in painting theory. Elegant contains the meaning of bleakness and quietness, and the literati respond with more ink and light colors. The colors of vulgar works are red and green, and it is weak in the ink, or it is swaying. It is a kind of rich and beautiful, red and green, magnificent momentum and ostentation. It is avoided by literati. Second is the mundane feeling, also known as the market air. It is mainly manifested in the fact that the painter is bound by fame and fortune without independent personality and integrity, which is the most contemptuous behavior of the literati. Moreover, it is vulgar, also known as craftsmanship. It is mainly reflected in the fact that the work is stiff, emphasizing skill but neglecting thoughts and the technique is too laborious, stale and lacks spirituality and innovative spirit.

\section{THE THEME OF Literati PAINTING}

Plum blossoms, orchid, bamboo and chrysanthemum is the most common subject of literati painting. Plum blossoms have self-esteem and bloom in winter, orchids are soft and clean, chrysanthemum has haughtiness and bamboo is quiet and modest. Chinese literati found their spiritual sustenance and perfect ideal personality from plum blossoms, orchid, bamboo and chrysanthemum, which becomes the means to express their aspiration.

\section{A. Plum Blossom Represents a Strong Character and Noble People Who Is Not Afraid of Virtue}

At the end of the Yuan Dynasty, Wang Mian was known for painting plum blossoms, especially for ink plum. He painted plum blossoms simple and free, with a unique style, showing a simple and wild atmosphere. His "ink plum drawing" paints cross-branched ink plum, of which the branches are quite showy, interspersed with the momentum. The painting is simple, and the composition is clear, which not only present the charm of the plum blossoms, but also express the artists' thoughts and feelings. In his "ink plum drawing", there is a poem saying: "On the tree at the pond of my house, all the flowers bloomed with light ink marks. They don't want people to praise the color, but just want to leave the elegant air in the world. "It can be seen that he used ink plum to express his high-spirited and unconventional quality.

\section{B. Orchid Has Elegant Appearance and Fragrant Flavor}

$\mathrm{Su}$ Shi associates its temperament with Qu Yuan's spirit. Orchids seem to be weak but contain moral integrity. They are not arrogant and attractive, natural and clean. Zheng Sixiao painted orchids most prominently. He put all his patriotic resentment on the orchids. His Molan drawing is light, and the leaves are stretched. The little ink is a bit of a flower. Zheng Sixiao's orchid has no roots and no soil, which is called orchard without root. It reflects that he does not collude with the new others and has sublime qualities.

\section{Bamboo Also Has a Gentleman Character}

After hardships and years of intrusion, it is still tough and stands upright. The gentleman is as open-minded as bamboo and hollow as bamboo. Wen Zhengming wrote a poem in his "Listening to jade": "The sound of Bamboo is good, and my ears are clear." The sound of bamboo should be distinguished by oneself. The high-hearted people are like bamboo while slim bamboos are like gentlemen."

\section{Chrysanthemum Is a Hermit Among Flowers}

It blooms after other flowers wither, with a tenacious vitality and high-spirited character. Zheng Sixiao wrote a poem in "Drawing Chrysanthemum": "The flowers don't bloom with other flowers, and the independence is infinite. It is better to hold the incense and die. It can be blow off in the wind. "This poem expresses the noble, unconventional, and the high-hearted character of the chrysanthemum, the persistence of ideals and beliefs, as well as the portrayal of his own purity.

In addition to the above-mentioned "four gentlemen", the lotus also has the character of "clear". "Lotus unsullied from mud, wash clean without demon. The middle pass is straight, the vines are not vines, the fragrance is far and clear, and the pavilion is purely planted." It is the temperament of the lotus flower and the gentleman-like character. The literati painters appreciate the natural and light beauty of the "water hibiscus", and rely on the lotus flower to pin their own high and clean personality.

\section{CONCLUSION}

The aesthetic value of literati painting is closely related to the artist's own moral quality and ideological cultivation. The artistic realm of literati painting is consistent with the artist's spiritual realm. "When the character is high, the rhyme has to be high, and the temperament is high and vivid. In the relationship between character and art, the core of painting is the mind of the literati, the soul of the literati, and the character determines the painting. It is not only the definition of morality but also the definition of art. Due to the social reality of the times, many literati painters have experienced ups and downs on the road of official career, but they are not discouraged or decadent, do not coexist with the world and are not flattered. They adhere to their own principles and morality, take advantage of the trend, and seclusion in nature. In the mountains and forests, they concentrate on the art of meditation by painting and cherishing, not rushing to dryness to cultivate inwardness and find a pure land of the soul in the world. This is a positive and courageous attitude of people in adversity. The works of literati paintings are mostly based on reality, facing the life, showing the truth, goodness and beauty, abandoning the evils of the society, pursuing spiritual freedom, pursuing the harmonious and perfect art form, and arousing people's thinking about life through profound expression of emotions, which has the meaning of aesthetic education. As a treasure of Chinese traditional culture, literati painting are not only the inheritance of painting skills, but also the inheritance of humanistic spirit. Starting from personality education, it 
seeks reference in literati painting. The quality of literati painting has both aesthetic value and moral value.

\section{REFERENCES}

[1] Liu Shang, Personality Cultivation and Contemporary Enlightenment in Art Education in the Yuan Dynasty [D]. Northeast Normal University. 2014.

[2] General Secretary Xi Jinping, "A Series of Important Speech Readers".

[3] Guo Juanjuan, Research on Art Education Thought in Confucius' "Six Arts" [D]. Nanjing University of the Arts. 2010.

[4] Sui Chao, The study of literati painting [D]. Shanxi Normal University. 2016.

[5] Hao Wenting. Research on the Aesthetic Implication of Chinese Classical Aesthetics "Qing" in Literati Paintings[D].Shandong University of Technology. 2015. 